\title{
A Study on Future Substitutes of Leather
}

\author{
Chaturvedi D* \\ Amity School of Fashion Technology, Amity University, India
}

*Corresponding author: Chaturvedi D, Amity School of fashion technology, Amity

University, Chhattisgarh, Raipur Campus, India.

Received Date: January 07, 2021

Published Date: February 26, 2021

\begin{abstract}
As we all are aware of that Leather is an ancient, durable material and most demanded because of its beauty and how it continues to look better and better after years of use. Leather is manufactured through derived skin of dead animals, most often made from cow hide. The process used to $\tan$ the skins, is treated with chemicals, many of them pollute land, water and air and can be harmful to workers. knowing this, should be choose to use an alternative or substitute for leather. For this we can go through leather history, its present manufacturing techniques, innovations in leather and what can be best possible substitute for leather in future in this particular research.
\end{abstract}

Keywords: Durable; Tan; Pollute land

\section{Introduction}

Leather is the finished result of tanning the crude covers up of a creature to make it strong but entirely adaptable. Leather is generally produced using cows stow away, however the skin from practically any creature (vertebrates, creatures of land and water, reptiles) including extraordinary creatures like ostriches, kangaroos, pythons and even camels can likewise be tanned into leather.

Leather merchandise and items have constantly been used by guy for a long time as a device of extravagance, assurance, consolation, application, fashion, and heat. The Indian dating with this profoundly adaptable and valuable material is going returned just about 5000 years. Today, leather remains viewed as an image of notoriety and prosperity.

Mashak's (Water sacks made of calfskin) had been usually utilized in India in the days of yore the primary recorded proof of calfskin suggests up inside the Hindu heavenly sacred writings of the Vedas. The Rig-Veda has recorded the utilization of leather 'Mashaks' or sacks as proper on time as 3000 B.C simply as jugs. The utilization of words, for instance, charmanta, charmapath, varatra, chasabandha which can be located in vintage Sanskrit writing display that lashes, agencies, and strings of cowhide had been in like way use in those days, portraying the chronicled estimation of calfskin and it is almost unfading interest esteem [1].

Calfskin making is a craftsmanship that is immortal and is woven into the feel of our first-rate country. through the ages, nation-states have traveled each which way, wars have been battled and freedom has been done via our super nation and the cowhide business alongside the lifestyle of calfskin making has made do via the entirety.

\section{Origin}

Leather making is an old workmanship that has been bored for more than 7,000 years. It's amazing state of shielding is solid confirmation that our archetypes have culminated the art of cowhide tanning and animal skin was made by the Egyptians and Hebrews around 400 BCE. During the Middle Ages the Arabs guarded the strength of leather making thus improved it that 
morocco and cordovan (from Córdoba, Spain) wound up being fundamentally regarded leather. By the fifteenth century, calfskin tanning was again expansive in Europe, and, by the mid-nineteenth century, power-driven machines that performed such exercises as separating, fleshing, and tanning were introduced $[2,3]$.

The leather business involves a position of unmistakable quality in the Indian economy taking into account its enormous potential for work, development and fares. There has been an expanding accentuation on its arranged turn of events, focused on ideal use of accessible crude materials for amplifying the profits, especially from trades.

\section{Manufacturing Process}

The leather produced using the escape different pieces of the creature has varying characteristics. For example, the leather produced using the escape the rear area is unique in relation to that on the stomach or shoulder. The leather fabricating measure is separated into three sub-measures: preliminary stages, tanning and crusting. A further sub-measure, surface covering might be added into the grouping. The rundown of tasks that leather go through fluctuate with the kind of skin. The leather making measure is all in all confined to clump preparing, yet in the event that the surface covering sub-measure is added, at that point some nonstop handling can be incorporated. The activity stream needs to follow the preliminary $\rightarrow$ tanning $\rightarrow$ crusting $\rightarrow$ surface covering sub-measure request without deviation, yet a portion of the subcycles can be precluded to make certain leather (or incompletely tanned/untanned items).

Three well known strategies for restoring are :

1. Wet Salting-The strategy includes use of a combination of salt and additive uniformly on the substance side by scouring admirably and heaping the $\mathrm{H} / \mathrm{S}$ tissue to tissue.

2. Dry Salting-This strategy is applied for longer safeguarding (proposed for long capacity or fare). The training is to rub the tissue side with an answer of khari salt and afterward to dry the $\mathrm{H} / \mathrm{S}$ in the shade. The last layer of salting regularly blended in with chalk so as to make the substance side white and alluring.

3. Drying-Two strategies for restoring by drying are:

a) Casing Drying: It comprises of extending the $\mathrm{H} / \mathrm{S}$ longwise on bamboo outlines and drying these in mellow sun uncovering the substance side to the sun. Fast drying under blistering sun isn't done to try not to frame a hard covering on fragile living creature and grain side.

b) Standard Drying: In this technique the H/S are spread out on the ground and dried under sun (Figure 1).

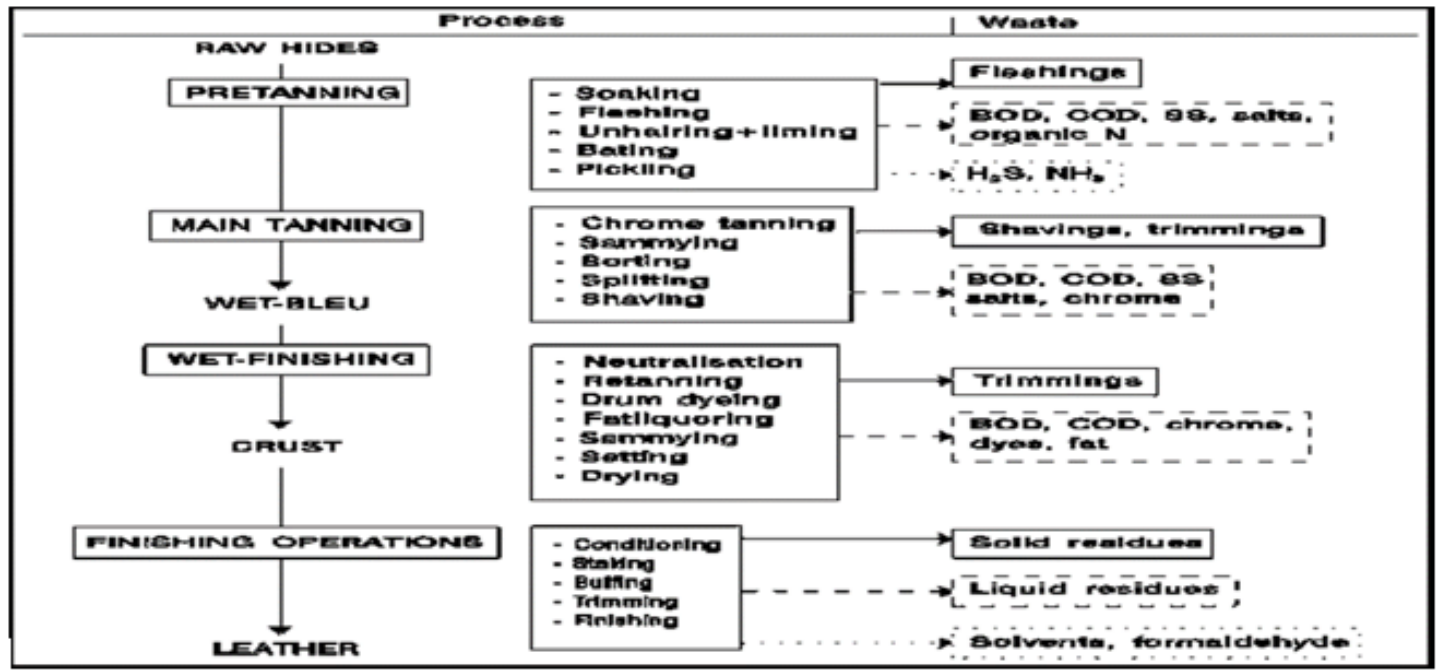

Figure 1.

\section{Steps of leather manufacturing}

1. Soaking - Hides are re-hydrated or re-splashed and washed in huge turning drums

2. Hair Removal - Hair is eliminated by substance processing (Lime and sodium sulfide arrangement). Bald covers up are then killed with acids and treated with chemicals Removes stores and builds delicate quality.
3. Deliming - Hairless stows away are then killed with acids and treated with proteins. It eliminates stores and furthermore builds delicate quality.

4. Pickling - Hides are absorbed an answer of water, salt, and hydrochloric (or Sulphur) corrosive

5. Tanning - there are two fundamental strategies for tanning Chrome and Vegetable. 
6. Vegetable tanning produces stiffer cowhides whereas chrome tanning produces milder c

7. Leather. Chrome Tanning is utilized generally for upholstery, shoes, articles of clothing, sacks. Shrouds set in pivoting drums and washed in a compound containing trivalent chrome. Following 8 hours, the chrome is "fixed" with a basic synthetic (sodium carbonate). Vegetable Tanning is utilized on shoe soles, gear, belts, and some upholstery it is Slower measure which requires 2-4 days. Utilizations tannic corrosive, which is separated from tree husk.

8. Dyeing - Placed in turning drums with heated water, colors, and engineered tanning materials to get wanted shading

9. Rolling - Rolled through a machine to make more grounded. Dried by hanging or dry tumbling.

10. Finishing - Finished with coatings of acrylic, urethane, vinyl, wax, nitro cellulose, color, or different materials.

\section{Impact of Leather Manufacturing Industry on Environment}

In the Initial phase Leather industry was one of the most dirtying ventures. The leather handling was liable for horrible effect on climate. The worldwide creation of leather is about $24 \mathrm{bn} \mathrm{m} 2$ that presents a significant test to leather industry. The tannery rich create high measure of broke up and suspended natural and inorganic solids that are offering ascend to high oxygen prerequisite. The terrible smell producing from squander material and presence sulfide, smelling salts and other unstable mixes are related with leather preparing exercises. With the passage of time different types chemicals are also used which trigger the process of making leather from animal skin but it pollutes environment also. As a result, various type water borne, air borne disease are taking place not only in industrial area but also in nearby residents [4].

The Leather business despite the fact that it has gained extensive ground in its relationship with the climate, it actually establishes a factor of forceful contamination because of the waste protein in nature, in unique those subsequent from tanneries and footwear plants. A piece of the sustainable improvement of the business is because of skin items, fabricated in wording of protecting the climate and in agreement with the biological system. Tackling misuse of the skin are a need to clean technologies, ecoaccommodating, since just $25 \%$ of crude skin is found as a finished item. Lessening contamination brought about by squander tanneries and the handling of finished products in the skin should be possible by discovering options in contrast to chromium arrangements or recycling solid squander [5].

\section{Substitutes of Leather}

Leather denotes cruelty to animals. Even bound religions condemn its use due to this. for example, several Hindus wouldn't use cow animal skin; and Jains wouldn't use any reasonably leather as a result of it's obtained by killing animals. additionally, there's another excuse why animal skin ought to be avoided: there's an enormous ecological impact of the animal skin business. Tanning could be an extremely harmful method and also the business itself is extremely energy hungry; manufacturing voluminous waste and pollution. For these and any variety of alternative reasons, the requirement to search out alternatives to animal skin is important; therefore, here is what you'll use rather than animal hides.

Innovative firms are initiating of the woodwork, introducing a replacement quite leather-like material. Mushrooms, pineapples, and active cultures have all been tapped to supply a a lot of property future for fashion. it's going to be arduous to believe that any of those things might be accustomed produce luxurious and trendy items, however they fully have the potential to try and do thus.

1. Faux Leather: There are numerous words for this: bonded leather (plastic leather), manufactured or fake leather, etc. Dissimilar to prior cowhide substitutes like Rexine, a considerable lot of these cutting-edge materials can have a lavish look and feel. A considerable lot of these counterfeit materials use plastics. For example, leatherette is made by overlaying texture with plastics.

2. Mushroom Leather: MusKin may be a leather like material produced using the covers of a mushroom type called Phellinus ellipsoideus. Not exclusively is that this mushroom cowhide designed in an eco-accommodating way, yet the use of Phellinus ellipsoideus alone is additionally earth gainful. This particular species is local to subtropical woodlands and "feeds on tree trunks," making them decay. Mushroom leather is an approach to sidestep the use of creatures and help keep our regular habitat solid simultaneously. it's water-repellent, nontoxic, and is sufficiently strong to form design things which might customarily be made out of leather.

3. Pineapple Leather: The most notable and broadly utilized leather elective within the pack is Piñatex's leather made out of pineapple leaves. English materials organization Ananas Anam, which was found out in 2013, was among the primary to return out with a plant-based leather elective. it's inventive method of extravagance materials without hurting the earth. It's delivered by utilizing crude materials which are the results of the pineapple reap, otherwise referred to as food squander, which is usually disposed of or consumed. Much an equivalent as MusKin, this pineapple leather is executing two (allegorical) winged creatures with one stone. Alongside the items' insightful assembling, Piñatex ${ }^{\circledR}$ additionally gives 'adaptable business open doors for provincial cultivating networks within the Philippines. While the imaginative material is incredibly manageable, it's additionally advanced into brands enormous and tiny, for instance , Hugo Boss, Po-Zu, Votch, and Nae. Pineapple leather remains within the beginning phases of selection, however getting the eyes of various because it disrupts all the rules of conventional creation. 
4. Tômtex: Coffee squander leather - Tômtex is produced using waste espresso beans and therefore the biopolymer chitin, which is found within the exoskeleton of shellfish and for this example is sourced from disposed of fish shells. The adaptable yet tough material utilizes the around 8,000,000 plenty of shells that are discarded by the worldwide food industry consistently.

5. Bio fabricated Leather: Modern Meadow is that the organization behind this new kind of material and has been changing the event game for quite a while. The group at Modern Meadow is concentrated on development and has delivered the organization's first image of bio fabricated materials, $\mathrm{Zoa}^{\mathrm{TM}}$. This impersonation cowhide is formed of what the organization calls 'nature's basic protein,' otherwise referred to as collagen. Their lab-developed leather is formed with no creature items or poisonous synthetic compounds. Zoa's leather may be a genuine stand-out item that's changing the way during which we consider how garments is formed.

6. Fungi-inferred leather: Leather substitutes are often created from growths by upcycling ease agrarian and ranger service results like sawdust. These fill in as 'feedstock' on which to develop mycelium - a tangled mass of lengthened parasitic strings, which become a sheet. Inside half a month, the parasitic sheet are often reaped and truly and artificially treated by squeezing and crosslinking to deliver a cloth with a comparable vibe to creature cowhide. This material comprises principally of biodegradable chitin and glucan biopolymers. These kinds of organisms determined leather might be exceptionally compelling to maintainability cognizant customers and organizations even as to the vegetarian network, which the business and purchaser hunger for bio-inferred leather choices like those from growths and cellulose is developing. Afterward it'll be "Inexhaustible, bio-determined garments may be a developing business, and contagious leather is popping into a promising new leader within the journey for economical and moral attire.

7. Cork Leather: This material is produced using the bark of stopper oak trees. Not exclusively is it brutality free it's additionally feasible since the tree rind becomes back inside a few of years.

8. Ocean Leather: This is often another leather substitute which will closely resemble leather. This material is understood as sea leather since it's produced using kelp, a kind of giant ocean growth. this is often a plentiful and manageable asset, which settles on this an environmentally solid decision also.

\section{Conclusion}

To conclude that in India, the Leather business is one among the principal prepared assortment organizations and holds concerning $100 \%$ of the overall staple for leather industry. The business has progressed into our storerooms likewise. Regardless, the leather stock is adding vogue to your shopper merchandise, in any case square measure adding to the executing of thousands of animals every day . Tanning, that will be that the ensuing stage, settles proteins inside the animal cover up and makes it stable for postponed use. Vegetable tones, metal salts, alum or perhaps mixed oils from the brains of skins square measure used for this technique. It is disappearing the sort of carbon footprint. Leather has been being utilized for a dreadfully significant time-frame , in various structures. In times, those drew in with harsh occupations and diversions advanced leather for its strong and safe nature [6]

Substitute leather execution is best than the genuine leather and subsequently the surface effect square measure frequently cultivated as per the genuine leather. It gives most prominent tear resistance, abrasion resistance, tensile strength around then on square measure all previous genuine leather, and cold-resistant, acid proof, alkali-resisting, non-fading, , anti-mildew, mothproof, without any harmful substances, very environmental. To boot they are lightweight in weight, Light in weight, soft, good breathability, smooth and good feeling, and tidy and free from wear facets. These kinds of leather require less maintenance, they are easy to cut, high utilization rate, easy to clean, no odors. By attentive blessing situation enduring substitute leather is that the ideal call for future as to such an extent as atmosphere to boot as cost resulted in lightweight of the established truth that they're doing not desert as significant an environmental impact. For sure, they help with reusing and upcycling conventional things [7].

\section{Acknowledgement}

None.

\section{Conflict of Interest}

Author declare no conflict of interest.

\section{References}

1. Covington AD (2009) Tanning Chemistry: The Science of Leather. Royal Society of Chemistry, UK.

2. Freeman RE (1984) Strategic Management: A Stakeholder Approach. Boston, MA, Pitman, USA.

3. Gopalkrishna WS (2002) Tannery Effluent focus on reverse osmosis" Business line.

4. (2005) The World is Flat, Friedman. P. 114

5. Williams AG, Audsley E, Sandars DL (2006) Determining the environmental burdens and resource use in the production of agricultural and horticultural commodities (DEFRA).

6. (2015) These Leather Alternatives Are Changing the Future of Sustainable Fashion.

7. (2020) Fungus leather substitute could be eco-friendlier than animal and plastic kinds. 